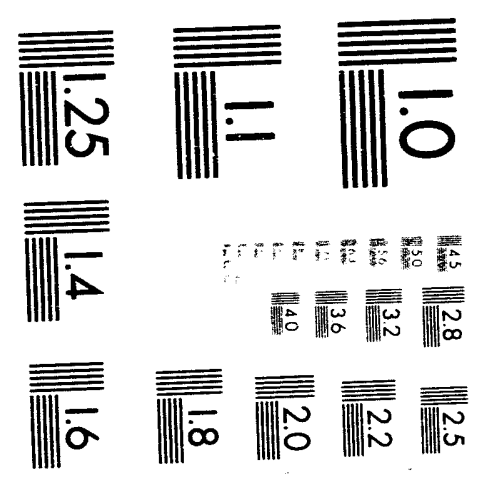



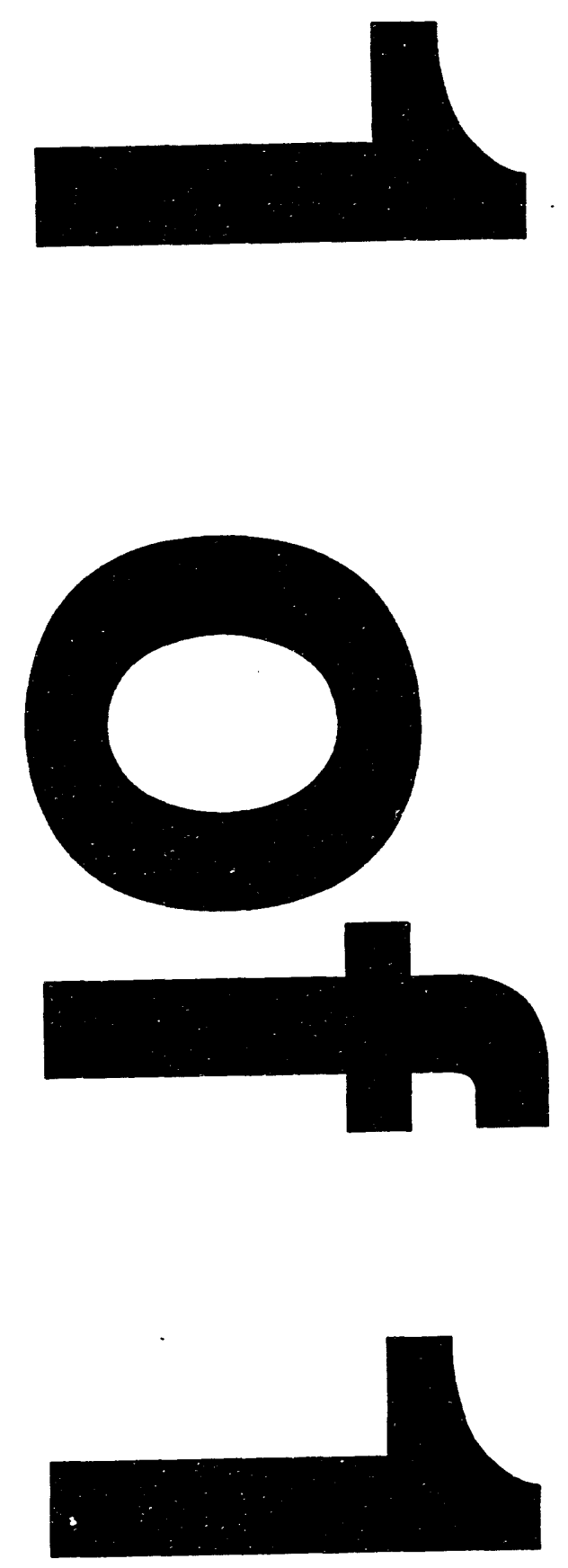
UCRL-ID-112617

\title{
Fuzzy Set Classifier for Waste Classification Tracking
}

\author{
Donald ${ }^{\top}$. Gavel
}

November 4, 1992 distribution. The opinions and conclusions stated are those of the author and may or may not be those of the Laboratory.

Work performed under the auspices of the U.S. Department of Energy by the Lawrence Livermore National Laboratory under Contract W-7405-Eng-48.

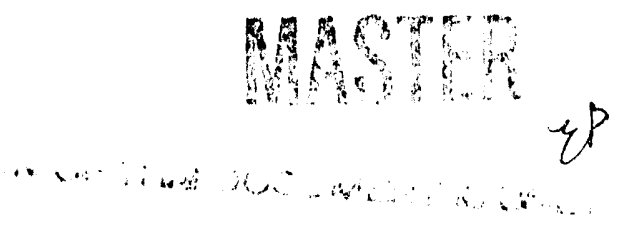


This document was prepared as an acccount of work sponsored by an agency of the United States Government. Neither the United States Government nor the University of California nor any of their employees, makes any warranty, express or implied, or assumes any legal liability or responsibility for the accuracy, completeness, or usefulness of any information, apparatus, product, or process disclosed, or represents that its use $\mathrm{v}$ 'ould not infringe privately own rights. Reference herein to any specific commercial products, process, or service by trade name, trademark, manufacturer, or otherwise, does not necessarily constitute or imply its endorsement, recommendation, or favoring by the United States Government or the University of California. The views and opinions of authors expressed herein do not necessarily state or reflect those of the United States Government or the University of California, and shall not be used for advertising or product endorsement purposes.

This report has been reproduced directly from the best available copy.

A vailable to DOE and DOE contractors from the Office of Scientific and Technical Information

P.O. Box 62, Oak Ridge, TN 37831

Prices available from (615) 576-8401, FTS 626-8401

Available to the public from the

National Technical Information Service

U.S. Department of Commerce

5285 Port Royal Rd.,

Springfield, VA 22161 


\title{
Fuzzy Set Classifier for Waste Classification Tracking
}

\author{
Donald T. Gavel \\ Advanced Process Technology Program \\ Lawrence Livermore National Laboratory \\ Presented at the \\ DOE Dismantlement Technology Forum \\ November 4, 1992
}

\begin{abstract}
We have developed an expert system based on fuzzy logic theory to fuse the data from multiple sensors and make classification decisions for objects in a waste reprocessing stream. Fuzzy set theory has been applied in decision and control applications with some success, particularly by the Japanese. We have found that the fuzzy logic system is rather easy to design and train, a feature that can cut development costs considerably. With proper training, the classification accuracy is quite high. We performed several tests sorting radioactive test samples using a gamma spectrometer to compare fuzzy logic to more conventional sorting schemes.
\end{abstract}

\section{Introduction}

The Department of Energy has an urgent need for the development of waste processing and cleanup technologies. Over the past few years, the Advanced Process Technology Program at Lawrence Livermore National Laboratory has been developing robotics and automation technology to support cleanup and reclamation efforts. In the Interactive Controls Laboratory we have devieloped a sensor-based robot system for material sorting tasks.

Robotic sorting of materials in a waste stream has been largely motivated by the DOE cleanup needs. A large fraction of the buried radioactive waste must be dug up and repackaged because contaminants are leaching into underground water tables. Hazardous waste stored in barrels at local sites must be resorted, according to federal guidelines, into categories of high level, low level, transuranic, and mixed waste, and disposed of accordingly. Certain materials, such as lead and stainless steel, can be reclaimed after being cleaned of radioactive contamination. Low level and mixed radioactive waste must be sorted into categories, such as burnable or vitrifiable, for later volume reduction and storage. Using robots instead of radiation suited workers reduces the exposure risk to humans, and also improves the reliability and speed of operation.

Weapons dismantlement is now an important issue. Technologies need to be developed to handle the waste materials derived from dismantlement. In particular, recycling of depleted uranium alloys has historically not been done, but new federal guidelines will require it. The recycling of alloys $\mathrm{U}-\mathrm{Ti}$ and $\mathrm{U}-\mathrm{Ni}$ will require segmentation and tracking in 0 . Jer to prevent cross contamination. 


\section{Fuzzy Set Classifier}

Unlike a standard industrial assembly line robot application, where parts and manipulation tasks are well defined, waste sorting is an unstructured task, where materials to be manipulated have unknown size, weight, and composition. The materials must be scanned by sensors located upstream and an intelligent robot control system must be able to decide what to do based on the sensory inputs.

We have developed an expert system based on fuzzy logic theory to fuse the data from multiple sensors and make waste material classification decisions 1 . Figure 1 shows a block diagram of the robot control system. Sensing instruments include an optical profiler, gamma spectrometer, metal detector, force sensor (for weight), and machine vision system. From these measurements we can infer size, density, metal content, and radiation content, then, using the rule base, determine if the object is lead, steel, plastics and other light materials, or radiation contaminated versions of these. The rule base consists of linguistic inference statements such as, for example:

(if weight is heavy and size is small then density is high)

(if density is high and inetal content is high then object is lead ).

These rules are derived from experience by human operators with the detectors and a set of known test items. These rules can be coded into a computer so long as the computer has an exact definition of terms like "heavy" and "high." As humans, we associate vaguely defined properties with these terms. To employ this same idea of vagueness in a rigorous mathematical context, a theory of fuzzy sets has been developed 2 . Within this theory, a new type of object, called the fuzzy set, is introduced which is a generalization of the ordinary set. Fuzzy set operations, analogous to the logical operations on ordinary sets, are defined accordingly (see Figure 2) and it is then a simple matter to implement a fuzzy logic inference engine on a computer. A fuzzy logic system takes input data from an experiment, applies the rules in its rule base, and comes up with conclusions. The output is a list of possible conclustons along with their degrees of confidence. If a hard decision must be made, as is the case in the waste sorting application (where the robot arm is instructed to place objects in various waste streams) then the conclusion with maximum confidence is taken.

\section{Experimental Results}

We performed an experiment using gamma spectrometer data to compare the fuzzy logic inference technique to a detection threshold method in categorizing radiation sources. In this experiment, four spectral bands resolvable by the sodium iodide detector were selected to correspond to strong emission lines of Americium 241 (50-70 kev), Thorium 232 (210-270 kev), Cesium 137 (600-730 kev), and Cobalt 60 (1270-1430 kev), respectively. However, since the emission spectra for these sources overlap, there is a possibility that information concerning the presence of Thorium, for example, is present in the Cesium band, and so on. Therefore, information useful in the categorization of radioisotopes is contained in the pattern of the counts, not just in the counts per individual band. The rules in the fuzzy rule base were set accordingly. For example,

(if band 4 is high or (band 4 is high and band 2 is high), then source is Cobalt 60). 
Results from one test are shown in Figure 3. Here, we tested sarnple sources located from 80 to $150 \mathrm{~mm}$ from the detector, and also made an equal number of tests with no source present. The fuzzy logic system correctly identified the isotopes with $100 \%$ accuracy, while the threshold system had only $94 \%$ accuracy (one false alarm) with a 200 count threshold, and $72 \%$ accuracy (four incorrect slassifications and two false alarms) with a 100 count threshold. As the sources are separated from the detector by larger distances the signal becomes weaker, so the sensor and fuzzy logic system begin to fail to detect the radiation. However, even with weak signals, the isotope signature is often still present. We set up the fuzzy logic system to guess the isotope, even if the radiation count was low. At average separations of roughly $300 \mathrm{~mm}$, the threshold system was failing nearly $100 \%$ of the time, while the fuzzy classifier was making correct guesses with about $50 \%$ accuracy.

\section{Conclusions}

We have used fuzzy set theory in the development of an expert system for hazardous waste sorting and classification. The knowledge base for a fuzzy logic system is oriented toward human linguistic thinking, and therefore easy to program by human experts. The system fuses data from multiple sensors to make reliable classification decisions.

Sorting and classification of materials will be a crucial task in the weapons dismantlement process. Special nuclear materials resulting from dismantlement need to be identified and tracked by an automated system to prevent unauthorized diversion from the recycle stream. The depleted uranium alloys should be segmented from each other to prevent cross-contamination. We see this as a future growth area for multisensor fusion and fuzzy classification systems such as the one we have developed.

\section{References}

1. A. Dougan, et. al, "Demonstration of Automated Robotic Workcell for Ha Lardous Waste Characterization," 1993 IEEE International Conference on Robotics and Automation (submitted).

2. L. A. Zadeh, "Fuzzy Sets," Information and Control, 8, 338-353, (1965). 


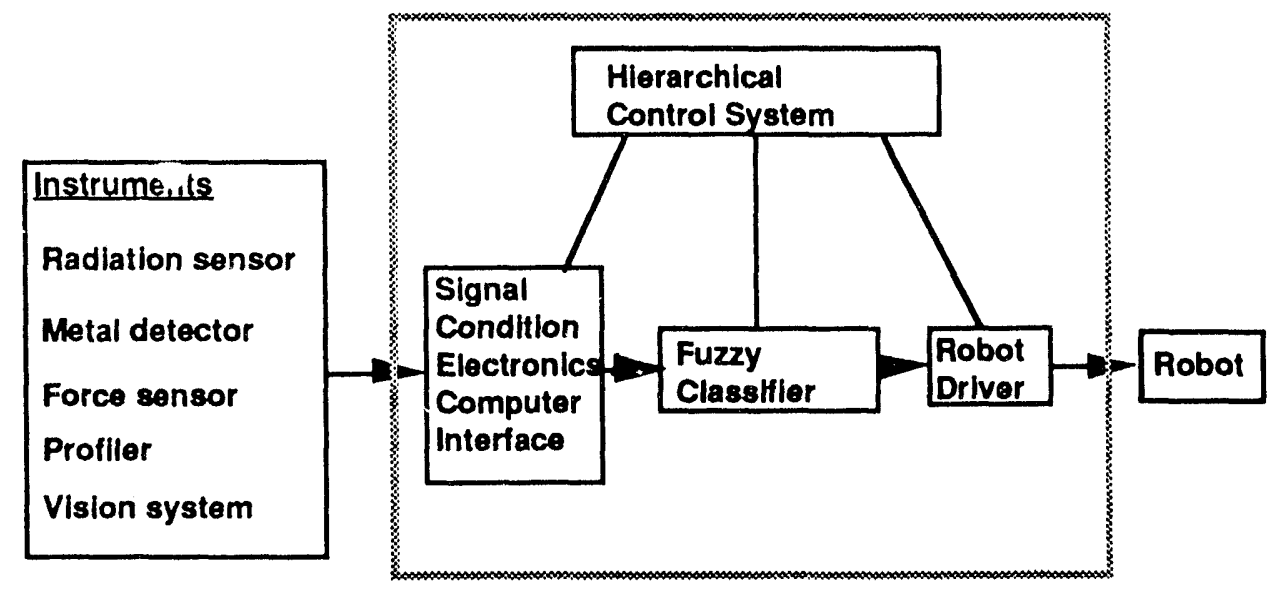

Figure 1. Block diagram of the robot control system. Input signals from various sensors are processed to determine the robot's next course of action. The fuzzy classifier categorizes the incoming material and provides this information to the robot driver.

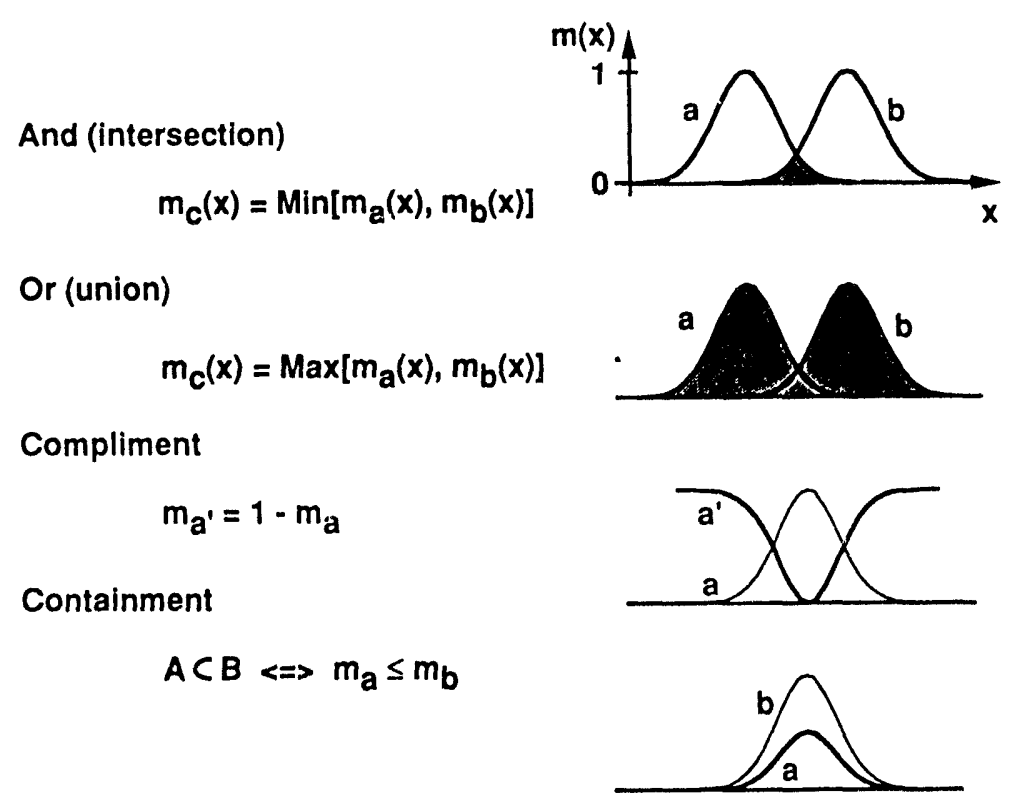

Figure 2. Operations on fuzzy sets. $x$ is a measured quantity. The membership function $m_{\alpha}(x)$ defines the boundaries of the fuzzy set $\alpha$. Membership in ordinary sets take on values in $\{0,1\}$ whereas fuzzy sets allow membership in the continuous range $[0,1]$. 


\begin{tabular}{|c|c|c|c|c|c|c|}
\hline $\begin{array}{c}\mathrm{Am} \\
\mathrm{bg}\end{array}$ & $\begin{array}{r}1789 \\
10\end{array}$ & $\begin{array}{r}.50 \\
24\end{array}$ & $\begin{array}{r}-43 \\
100\end{array}$ & $\begin{array}{l}4 \\
2\end{array}$ & $1 \mu \mathrm{Ci}$ sample & \multirow{14}{*}{$155 \mathrm{~mm}$} \\
\hline Cs & 15 & 5 & 2020 & 23 & $1 \mu \mathrm{Cl}$ sample & \\
\hline $\begin{array}{l}\mathrm{bg} \\
\mathrm{Am}\end{array}$ & $\begin{array}{r}15 \\
1719\end{array}$ & $\begin{array}{r}-48 \\
48\end{array}$ & $\begin{array}{l}33 \\
20\end{array}$ & $\begin{array}{r}-16 \\
6\end{array}$ & & \\
\hline bg & 6 & 66 & 23 & -21 & & \\
\hline Co & 24 & 112 & 3 & -16 & $1 \mu \mathrm{CI}$ sample & \\
\hline $\begin{array}{l}\mathrm{bg} \\
\mathrm{Am}\end{array}$ & $\begin{array}{r}11 \\
2043\end{array}$ & $\begin{array}{l}58 \\
28\end{array}$ & $\begin{array}{r}3 \\
-88\end{array}$ & $\begin{array}{l}-16 \\
-24\end{array}$ & & \\
\hline bg & 24 & -16 & 11 & -2 & smoke detector & \\
\hline Th & -243 & 1298 & -377 & -37 & Coleman lantern mantels & \\
\hline 6 & (p) & 161 & 59 & som & & \\
\hline Th & 88 & 120 & -368 & 40 & welding rods (under box) & \\
\hline $\begin{array}{c}\text { Th } \\
\text { bg }\end{array}$ & $\begin{array}{r}303 \\
-6\end{array}$ & $\begin{array}{r}1187 \\
72\end{array}$ & $\begin{array}{r}-1699 \\
2\end{array}$ & $\begin{array}{r}-52 \\
-9\end{array}$ & welding rods (on top of box) & \\
\hline Th & -520 & 13309 & -7058 & -146 & lens & \\
\hline Th & -891 & 3111 & -1070 & 86 & mantels & \\
\hline Co & -16 & 120 & -26 & 953 & $1 \mu \mathrm{Cl}$ sample & \\
\hline
\end{tabular}

- Accuracy (this sample)

Fuzzy logic: $100 \%$

200 count threshold: $94 \%$ 100 count threshold: $72 \%$

Figure 3. Results from an isotope identification experiment. The highlighted area indicates where the threshold algorithm with a 100 count threshold produces a false alarm (background misidentified as Thorium 232). The fuzzy logic system, relying more on pattern recognition, correctly indicates this as backgruund radiation, i.e., no source present. Some "counts" are negative because of data preconditioning and normalization. 

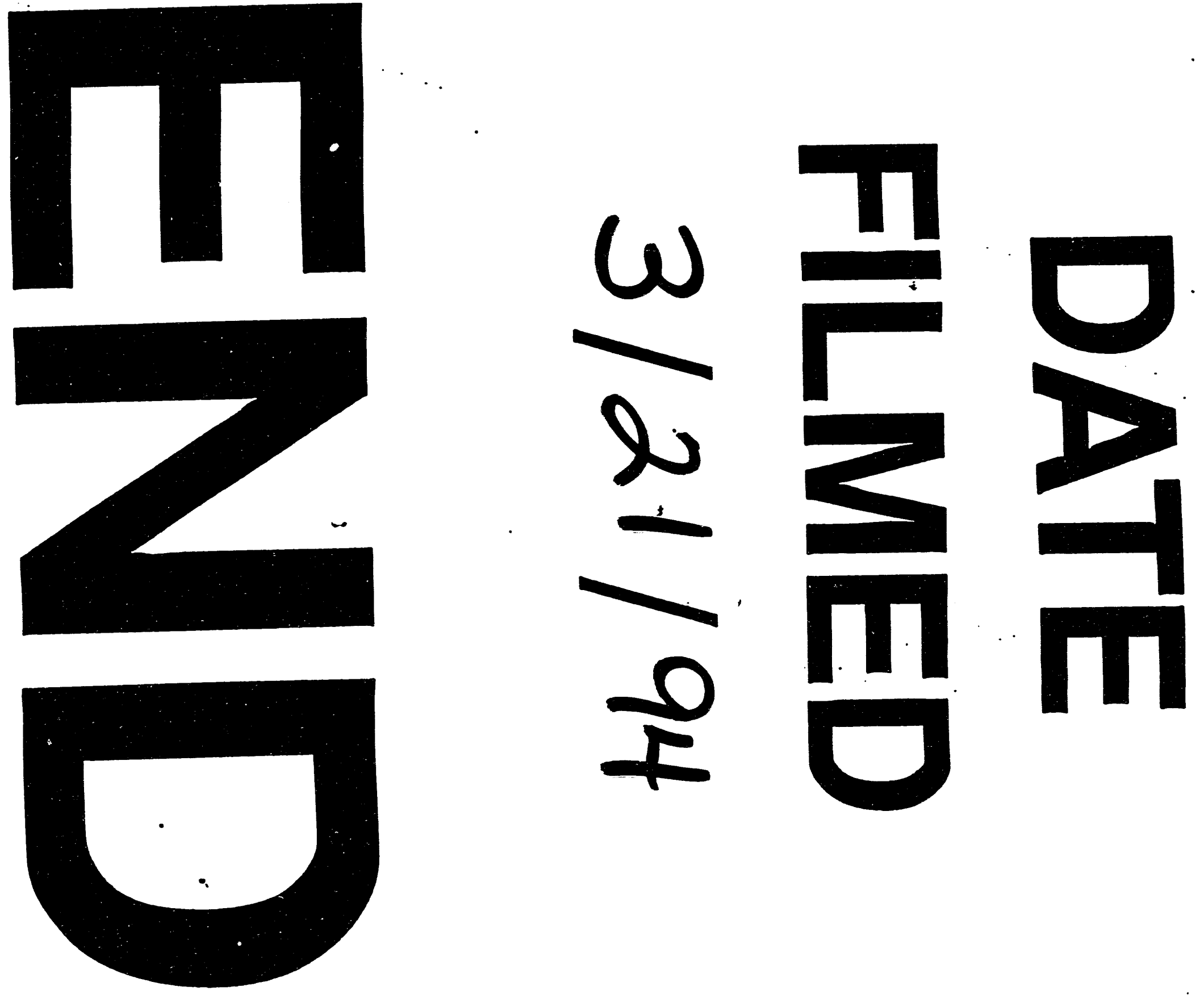
